\title{
Talent Engagement Drivers And Employee Productivity In Technical Vocational Education Training Institutions In Kenya.
}

\author{
Christine Kananu Gitonga ${ }^{1}$ Dr. Robert Egessa ${ }^{2}$ \\ ${ }^{1} \mathrm{PhD}$ candidate (Human Resources Management), Masinde Muliro University of Science and Technology \\ ${ }^{2}$ Lecturer, School of Business and Economics, Masinde Muliro University of Science and Technology \\ DOI: 10.29322/IJSRP.11.05.2021.p11347 \\ http://dx.doi.org/10.29322/IJSRP.11.05.2021.p11347
}

\begin{abstract}
Training and human resource development is an important component in any given learning organization. Kenya, as a developing economy has put in place parameters to spearhead its growth namely; Vision 2030 which recognize the critical role of science, technology, innovation and training in moving the country to a middle income status. The productivity of workers in Technical colleges is very critical in ensuring workers and the general performance of Technical Colleges to meet the set objectives that are normally spelled out in their five year strategic plans as well as annual objectives. Extensive literature review shows little has been documented on talent engagement drivers and employee productivity in Technical Vocational Education Training Institutions in Kenya. Therefore, this study sought to investigate influence of talent engagement drivers on employee productivity in Technical Vocational Education Training Institutions in Kenya. A population is a complete set of units to be studied (Kothari, 2004). The study was anchored on resource based view and Human Capital theories. A positivistic philosophy was adopted in order to investigate relationships among the variables. Descriptive and correlation research designs, which led to mixed research design was adopted in this study. The population of the study included all of TVET institutions in Kenya. There is a total 629 TVET institutions (GoK, 2013). Therefore the target population was all the 629 TVET institutions in Kenya. Using Fisher formula, 238 institutions were selected to participate in the study as the sample size. The Research design the study used is the descriptive survey design. Data was analyzed using inferential statistics. This involved the use of correlation and regression modelling .From the results, the correlation between talent engagement drivers and employee productivity was 0.893 at $\mathrm{p}=0.000$. This implied that there was a statistically significant positive relationship between talent engagement drivers and employee productivity. From the results, the F-statistics was recorded as 896.581 at $\mathrm{p}=0.000$, at $95 \%$ confidence level, implied the model was fit to explain the relationship between talent engagement and employee productivity. The study therefore rejected the null hypothesis and concluded that there was a statistically significant positive relationship between talent engagement drivers and employee productivity in TVETs in Kenya.
\end{abstract}

Index Terms- Talent Engagement Drivers, Employee Productivity, Technical Vocational Education Training Institutions, Kenya

\section{INTRODUCTION}

A s noted by Patro (2013), over the past decade, globally, many authors have written on the topic 'Employee Engagement'. Kahn (1990) was the first to coin the term engagement as he described how people can "use varying degrees of their selves physically, cognitively and emotionally in work role performances". Employee engagement is not the only term used to describe the positive attitudes and behavior of employees at work. Other terms commonly used are 'commitment', 'organization citizenship behavior' and the 'psychological contract'. The policy and practice implications of employee engagement are often captured in 'high involvement work practices' and 'high performance working'. Employee Engagement is arguably the most critical metric for organizations in the 21st Century. Employee engagement is directly influenced by growth of the organization, value addition experienced by employees and employee perception of the organization.

Human resource practitioners believe that the engagement challenge has a lot to do with how employee feels about the about work experience and how he or she is treated in the organization (Patro, 2013). It has a lot to do with emotions which are fundamentally related to drive bottom line success in a company. Employee engagement initiative has a direct impact on the organization's productivity. The concept of engagement has naturally evolved from past research on high involvement, empowerment, job motivation, organizational commitment, and trust. The key factors in engagement are such as alignment of employees toward strategy; enabling employees to have the capability to engage them-selves; and creating the sense of engagement. This multi-faceted nature of employee engagement is well captured by the Employee Engagement Consortium at Kingston University. The researchers say that: 'fundamental to the concept of employee engagement is the idea that all employees can make a contribution to the successful functioning and continuous improvement of organizational processes. Engagement is about creating opportunities for employees to connect with their colleagues, managers and the wider organization. It is about creating an environment where employees 
are motivated to want to connect with their work and really care about doing a good job' (Patro, 2013).

At this critical time, the increased attention from the government to employee engagement is highly required and will lead to achieving the government's goals, as well as, increase its productivity. Gallup's study, which was demonstrated on 142 countries in 2015; showed that $13 \%$ of Egypt's employees are engaged and mentally committed to their jobs and likely to be making positive contributions to their organizations. However, $55 \%$ of Egypt's employees are not engaged and 32\% are unhappy and unproductive. This is an indication for a big problem (Gallop Study, 2015) (Hanan, et al., 2014). Managers should promote engagement for numerous reasons, such as the employees' mental health; it was found that engaged employees have healthier mental state and tend to be more productive than employees who are not engaged, which affects the organization's competitive advantage(May, et al., 2004). Moreover, a clear strong relationship between productivity and organizational performance was found; the higher the employee engagement, the better the financial performance, the less the turnover rate, and the higher the productivity (Baumruk, 2006).

\section{Talent Engagement Drivers}

Talent engagement drivers can efficiently and effectively lead to employee engagement. Those drivers are represented in; the job's nature, an individual's relationships with coworkers as well as personal relationship with one's manage, employee development opportunities, the organization's culture, the communication's quality, the management's styles, and the levels of trust and respect within the organization (Lockwood, 2007). The levels of engagement and its drivers are not constant; however, they differ from one organization to the other; due to numerous factors, such as: the different organizations' structures, cultures and policies, the different employee groups, and the different individuals and jobs (Robinson, 2007. The most important drivers for engagement can be considered the involvement, career progression, training and development, communication, one's belief in company's path, and participation in company decisions (Robinson et al., 2007).

\section{Employee Productivity}

According to Ali and Adan (2013), productivity is described as the production of goods and services with the least effort. These authors further clarified productivity as being the ratio that measures how well an organization (or individual, industry, country) converts input resources (e.g. labour, materials, machines) into goods and services. Atkinson (2013) defined productivity as being "an economic output per unit of input". Feige, Wallbaum, Janser and Windlinger (2013) stated that productivity was "the ratio of output to input depending on the context and content of the output measure (e.g. products, services, market shares, value) and input measure (for example cash, labour, energy, materials, and work environment)." For Yi and Chan (2013), productivity is the efficiency and the rate at which goods are produced. They further described it as "being used to denote a relationship between output and the associated inputs used in the production process", and said it is a measure of outputs obtained by a combination of inputs. In general, productivity is about efficiency in relation to the rate of output, per unit of input (Meyer,
Fritz, Murphy and Zimmermann, 2014). In practical terms, productivity refers to the employee's continuous efforts to convert inputs into outputs efficiently and sustainably - in pursuit of meeting the organizational goals.

\section{Statement Of THE Problem}

Kenya's economic growth is hinged on adoption of knowledge based economy. Consequently, the critical role that research, technology and innovation are expected to play in moving the country to a middle income status as well as the role of a well-trained public service in enhancing efficiency and effective service delivery have been aptly captured in the country's economic blue print; Vision 2030 (RoK, 2007). However, the performance of the public service in general and of state corporations in particular has been a matter of great concern to the government and the general public (RoK, 2013).

Employees are the key assets to any organization and if they are not given the right space and time to make a perfect blend of work and fun at workplace, then the sense of dis-engagement sets in the employees. Organization and employees are both dependent on each other to fulfil their goals and objectives. Therefore, employee engagement should not be a one-time exercise but it should be integrated in the culture of the company. Employee engagement should be a continuous process of learning, improvement and action. Thus, organizations today should actively look forward to fulfil employee`s expectations and thus, create an impact on the performance of employee, which directly affects the organization's performance.

Several studies on engagement drivers and employee productivity have been carried out. A study on drivers of engagement by Mani (2011) predicted four drivers, namely employee welfare, empowerment, employee growth and interpersonal relationships (Mani, 2011), Seijit (2006) identified the $10 \mathrm{Cs}$ of Employee Engagement, namely Connect, Career, Clarity, Convey, Congratulate, Contribute, Control, Collaborate, Credibility \& Confidence. The three elements of employee engagement, viz contributions, connections, growth and advancement, were identified through a study by Wallace et al., (2006), as cited in Mani, 2011. Britt et al (2001) predicted employee involvement and commitment as engagement drivers. Study by IES in 2004 identified the following as predictors: leadership, relationships at work, total reward, recognition, work life balance and work itself. Study by IES (2005) identified the following drivers: job satisfaction, feeling valued and involved, equal opportunity, health and safety, length of service, communication and co-operation. A study by Towers Watson (2009) identified following three predictors of engagement; rational (how well the employee understands roles/responsibilities), emotional (how much passion employee can bring to work) and motivational (how willing is the employee to invest discretionary effort to perform their role). The said studies were done outside Kenya and used different constructs to define talent engagement drivers. The motivation of the current study was therefore to investigate effect of talent engagement drivers on employee productivity in Technical Vocational Education Training institutions in Kenya. 


\section{OBJECTIVE OF THE STUDY}

The general purpose of the study was to investigate effect of talent engagement drivers on employee productivity in Technical Vocational Education Training institutions in Kenya.

\section{Research Hypothesis}

H01: Talent engagement drivers has no effect on employee productivity in Technical Vocational Education Training institutions in Kenya

\section{Conceptual Framework}

Figure 1.1 show the conceptual framework that guided the present study.

Independent Variable (Talent Engagement Drivers)
Dependent Variable

(Employee Productivity)
- Job Design

- Leadership style
- Business Continuity

- Climate of Commitment and trust

Figure 1.1: Conceptual Framework showing the interaction between talent engagement drivers and employee productivity in Technical Vocational Education Training Institutions in Kenya.

\section{Source: Researcher's own Conceptualization, 2021.}

\section{LITERATURE REVIEW}

\section{Theoretical Foundations}

Theoretical framework guides research to determine what things to measure, and what statistical relationships to look for (Defee, Randal, Thomasd \& Williams, 2010). This study was guided by resource based view and human capital theory as discussed in the subsequent sections.

\section{Resource Based View (RBV)}

Resource Based View (RBV) was developed by Edith Penrose in 1959. She looked at an organization as a collection of physical and human resources bound together in an organizational structure. Physical assets which include systems are easily distinguishable due to their tangible existence while human resources (intellectual assets) which include employee skills and staff knowledge are considered as intangible assets. Resource based view indicates that a resource which must be currently scarce, difficult to imitate or copy, non-substitutable and not readily accessible in factor markets to create competitive advantage should provide economic value that determines organizational performance (McIvor, 2009).

Scholars subscribing to RBV argue that only strategically important and useful resources, core competencies and capabilities such as shared values and strategy should be viewed as sources of competitive advantage that leads to improved organizational performance. Core competencies provide an organization with a potential competitive edge and are distinctive, rare, valuable firmlevel resources that competitors are unable to imitate, substitute or reproduce (Barney, 2007). RBV was deemed relevant to this study since it informed both the independent and moderating variables.

\section{Human Capital Theory}

Human Capital Theory (HCT) of Schultz (1975) presumes that education or training had the potential for stimulating economic growth, technological progress and productivity because it transferred useful knowledge and skills for better life time earnings (Ladipo et al., 2013). On the other hand, Klein and Cook (2006) acknowledged that investing in people was a form of human capital which propelled changes in the society. Like other forms of human capital, human hands-on ability could be increased through education and training experience.

Globalization has complicated the way of doing business and thus enforcing most organizations to invest in human resources as a source of competitive advantage. The world was experiencing a revolution in information technology, innovation, and telecommunications, which was driving the emergence of the knowledge-based economy (Chan, 2002). The accumulation of human capital improves labor productivity, facilitates technological innovations, increases returns on capital and makes growth more sustainable in any organization. This theory supported the independent, moderating and dependent variables as it contained the elements that form the variables.

\section{EMPIRICAL LiteratURE REVIEW}

According to Xu and Thomas Cooper (2010) leadership is a key precursor of engagement. Leadership research shows that certain leadership behaviors have clear association with engagement constructs such as motivation, job satisfaction, organizational commitment, proactive behaviors and organizational citizenship behavior. Trust in leader, support from the leader, and creating a blame-free environment are considered as components of psychological safety, a condition proposed by Kahn, which leads to employee engagement ( $\mathrm{Xu}$ and Thomas Cooper, 2010). Studies by Judge and Piccolo (2004), Lee (2005), Erkutlu (2008), Griffin et al., (2010) provide evidence for association between positive leader behaviors and follower attitude and behaviors linked with engagement. A few other studies have attempted to provide direct evidence of association between leadership and employee engagement (Xu and Thomas Cooper, 2010). 
A study by Atwater and Brett (2006, as cited in Xu and Thomas Cooper (2010) identifies three leadership behaviors, namely employee development, consideration and performanceorientation. The first two behaviors are labelled relationshiporiented and the third as task oriented. They further state that employee engagement includes facets of work on which leaders can take action. Metcalfe and Metcalfe (2008) present positive correlation between leadership scales and engagement constructs such as job and organizational commitment, motivation and job satisfaction. Papalexandris and Galanki (2009) identify two factors which are positively linked with engagement, namely, management and mentoring behaviors such as imparting confidence to followers, power sharing, communication, providing role clarification and articulation of vision which could be characterized as inspirational, visionary, decisive and teamoriented. More importantly, their study found only certain leader behaviors are associated with engagement, especially those enhance follower performance and which enable followers to relate with organizational goals. Studies by May et al., (2004), Saks (2006), Bakker et al., (2007) show that higher levels of engagement are observed for employees with their supervisors exhibiting more relationship-related behaviors ( as cited in $\mathrm{Xu}$ and Thomas Cooper (2010).

According to Khan (1990) for employee engagement take place, three perquisites conditions ought to be met; the job has to be worthwhile, the work environment should be supportive and based on trust and the employee should have emotional and physical capacity to engage. These conditions are influenced by the organization's human resource management practices (HRMP which are positively related to psychological empowerment that results to intrinsic motivation and increased work performance and organizational outcomes (He, 2014). Employee engagement is therefore a product of a healthy work culture and institutional support.

Another study by Grants (2008) on task significance found that it increases job dedication and cooperative behavior among employees by enabling employees to find meaning in their work leading to more involvement. This elicits discretionary effort from the employee and thus positively influences performance. However, job involvement does not affect performance directly but do so through its impact on other outcomes such as organizational commitment (Chughtai, 2008) and hence the need to test the effect of task significance on organizational performance while including a mediator such as organizational commitment.

\section{RESEARCH Methodology}

\section{Research Design}

This study adopted a descriptive survey research design alongside the correlation research design which lead to mixed research design. Mixed research design is preferred on the grounds that it is not only for collecting data, but also for investigating and attempting to establish the existence of certain relationships among dependent and independent variables which have already occurred. It is used for collecting information about peoples' perceptions and attitudes (Mugenda, 2008).

According to (Mertler, 2017), in this design, the researcher does not manipulate the variables under study but instead, examines the variables in their existing condition. Mixed methods research is preferred in this study because; it helps explain, clarify and extend results of research; answers research questions that may require both types of data; one type of data and analysis may be used to offset the weaknesses of the other; and it is seen as more practical (Mertler, 2017).

\section{STUdY POPULATION}

A population is a complete set of units to be studied (Kothari, 2004). The population of the study included all of TVET institutions in Kenya. There is a total 629 TVET institutions (GoK, 2013). Therefore the target population was all the 629 TVET institutions in Kenya.

\section{Sample Size and Sampling Procedure}

A sample is a subset of a population (Kothari, 2004). Since the population was less than 10,000 , the fisher et al, (2003) formula was employed. The Fisher formula is as follows:

$n=\frac{z^{2} p(1-p)}{d^{2}}$

Where;

$n=$ sample size

$z=$ the standard normal deviate value for the level of confidence, for instance $95 \%$ level of confidence $=1.96$.

$d=$ margin of error or level of precision at 0.05 for CI at $95 \%$ $p=$ proportion to be estimated, Israel (2009) recommends that if one doesn't know the value of $p$ then you should assume $p=0.5$ Therefore, sample size was arrived at as follows:

$n=\frac{\left(1.96^{2}\right)(0.5)(1-0.5)}{(0.05)^{2}}$

$n=384$

Since the population is less 10,000 , the sample size is further adjusted as follows:

$\mathrm{n}_{0}=\mathrm{n} /(1+((\mathrm{n}-1) / \mathrm{N}))$

$\mathrm{n}_{0}=384 /(1+((384-1) / 629))$

$\mathrm{n}_{0}=238$

Therefore the sample size was 238 employees of TVET in Kenya who were selected using stratified random sampling.

\section{Research data and sampling Techniques}

Primary data collection was done through administering of the questionnaire to the sample population in the study. Secondary data was obtained from published and unpublished sources including books, projects reports, magazines and other relevant materials in libraries and archives regarding to the application and development of knowledge sharing in different organizations and higher education. Internet search also formed an important part of secondary data. 


\section{DATA ANALYSIS}

Quantitative data was analyzed using inferential statistics. This involved the use of correlation and regression modelling

\section{Study Results and Findings}

Hypotheses Testing

The following null hypothesis guided the study;

Table 4.1 Correlation between Talent engagement drivers and Employee Productivity

\begin{tabular}{llll}
\hline & & $\mathbf{1}$ & \multicolumn{1}{c}{$\mathbf{2}$} \\
\hline Talent engagement Drivers & Pearson Correlation & 1 & $.893^{* *}$ \\
$(1)$ & Sig. (2-tailed) & 140 & .000 \\
& $\mathrm{~N}$ & $.893^{* *}$ & 140 \\
Employee Productivity & Pearson Correlation & .000 & \\
$(2)$ & Sig. (2-tailed) & 230 & 230 \\
**. Correlation is significant at the 0.01 level (2-tailed). & & \\
\hline
\end{tabular}

From the results in Table 4.1, the correlation between talent engagement drivers and employee productivity was 0.893 at $\mathrm{p}=0.000$. This implied that there was a statistically significant positive relationship between talent engagement drivers and employee productivity.

Table 4.2 ANOVA Test between Talent engagement Drivers and employee Productivity

\begin{tabular}{|c|c|c|c|c|c|c|}
\hline $\begin{array}{l}\mathbf{A N O V} / \\
\text { Model }\end{array}$ & & Sum of Squares & $\mathrm{df}$ & Mean Square & $\mathrm{F}$ & Sig. \\
\hline & Regression & 1629.266 & 1 & 1629.266 & 896.581 & $.000^{\mathrm{b}}$ \\
\hline 1 & Residual & 414.321 & 139 & 1.817 & & \\
\hline & Total & 2043.587 & 230 & & & \\
\hline $\begin{array}{l}\text { a. Depe } \\
\text { b. Predi }\end{array}$ & $\begin{array}{l}\text { ident Variab } \\
\text { ctors: (Const }\end{array}$ & $\begin{array}{l}\text { Employee Product } \\
\text {, Talent engagem }\end{array}$ & $\begin{array}{l}\text { y } \\
\text { Driver }\end{array}$ & & & \\
\hline
\end{tabular}

From the results in Table 2, the F-statistics was recorded as 896.581 at $\mathrm{p}=0.000$, at $95 \%$ confidence level, implied the model was fit to explain the relationship between talent engagement and employee productivity.

The study therefore rejected the null hypothesis and concluded that there was a statistically significant positive relationship between talent engagement drivers and employee productivity in Technical Vocational Education Training Institutions in Kenya.

\section{CONCLUSION}

There was a statistically significant effect of talent engagement drivers on employee productivity in Technical Vocational Education Training Institutions in Kenya.

\section{RECOMMENDATION}

There is need for Technical Vocational Education Training Institutions in Kenya to enhance job design and leadership style since they have an effect of employee productivity in Technical Vocational Education Training Institutions in Kenya.

\section{SUGGEstions FOR FURTHER RESEARCH}

The study was carried out in Technical Vocational Education Training Institutions in Kenya. Future studies are encouraged to be carried out in other learning and training institutions to compare the universities.

\section{REFERENCES}

[1] Abrahams, S. (2012). Job satisfaction as an antecedent to employee engagement. SIES Journal of Management, 8(2), 27-36.

[2] Abukhalifer, A. N. \& Som, A. P. M. (2013). The antecedents affecting employee engagement and organizational performance. Asian Social Science, 9(7).

[3] Adair, C., Macpherson, D. \& Oehler, K. (2017). 2017 trends in global employee engagement. Aon Hewitt.

[4] Ahmed, M. \& Dajani, Z. (2015). The impact of employee engagement on job performance and organizational commitment in the Egyptian banking sector. Journal of Business and Management Studies, 3(5).

[5] Ali, A. Y. S., Ali, A. A. \& Adan, A. A. (2013). Working conditions and employees"e productivity in manufacturing companies in sub-saharan African context: Case of Somalia. Educational Research International, 2(2).

[6] Anita, J. (2014). Determinants of employee engagement and their impact on employee performance. International Journal of Productivity and Performance Management, 63(3), 308-323.

[7] Anitha, J. (2014). Determinants of employee engagement and their impact on employee performance. International Journal of Productivity and Performance Management, 63(3). 
[8] Anyadike, N. O. (2013). Human resource planning and employee productivity in Nigeria public organizations. Global Journal of Human Resources Management, 1(4), 56 -68.

[9] Ariani, D. W. (2013). The relationship between employee engagement, organizational citizenship behaviour, and counter-productive work behavior. International Journal of Business Administration 4(2), 46-56

[10] Atkinson, R. D. (2013). Competitiveness, innovation and productivity: Clearing up the confusion. The Information Technology, 1-7.

[11] Bakker, A. B., Demerouti, E. \& Sanz-Vergel, A. I. (2014). Burnout and work engagement: The $\mathrm{jd}-\mathrm{r}$ approach. The Annual Review of Organizational Psychology and Organizational Behavior.

[12] Baumruk, R. (2006), why managers are crucial to increasing engagement, Strategic HR Review,

[13] Berdarkar, M. \& Pandita, D. (2014). A study on the drivers of employee engagement impacting employee performance. Procedia - Social and Behavioral Sciences.

[14] Bersin, J. (2015). Becoming irresistible: A new model for employee engagement.

[15] Bhuvanaiah, T. \& Raya, R. P. (2014). Employee engagement: Key to organizational success. Journal of Indian Management.

[16] Bryman, A. \& Bell, E. (2012). Business research methods, New York, Oxford University Press Inc.

[17] Chughatai, A. (2008). Impact of job involvement on in-role job performance and organizational citizenship behavior. Research paper, Dublin City University.

[18] Dulagil, A. (2012). The relationship of employee engagement and wellbeing to organizational and student outcomes. SBS HDR Student Conference.

[19] Farouk, I. (2014). Exploring employee attitude and productivity at electricity company of ghana, ashanti-east. Journal of Human Resources Management $5(4)$.

[20] Feige, A., Wallbaum, H., Janser, M. \& Windlinger, L. (2013). Impact of sustainable office buildings on occupant's comfort and productivity. Journal of Corporate Real Estate, 7-34. Gallup. (2016).

[21] Gandy, W. M., Coberley, C., Pope, J. E. \& Wells, A. (2014). Comparing the contributions of well-being and disease status to employee productivity. Journal of Occupational and Environmental Medicine, 56(3), 252-257.

[22] Geldenhuys, M., Laba, K. \& Venter, C. M. (2014). Meaningful work, work engagement and organizational commitment. Journal of Industrial Psychology, 40(1)(1).

[23] Gems, E. (2015). New perspectives in employee engagement in human resources, UK, Emerald Group Publishing Limited.

[24] Grants, A.M. (2008). The significance of task significance: Job performance effects, relational mechanisms and boundary conditions. Journal of Applied Psychology Vol. 93(1), 108-124

[25] Hair, J. F., Celsi, M. W., Money, A. H., Samouel, P. \& Page, M. J. (2011). Essential of business research methods New York, M.E. Sharpe.

[26] Hanan M.; Antoine L. and Sanchez, C. (2014). Growing without changing. A tale of Egypt's weak productivity growth. Working paper No. 172, European Bank for reconstruction and development

[27] Harter, J. K., Schmidt, F. L., Agrawal, S. \& Plowman, S. K. (2013). The relationship between engagement at work and organizational outcomes.

[28] He, J. (2014). From employee perceived human resource practices to employee engagement. The influence of psychological empowerment and intrinsic motivation. A paper presented at international conference on management science and management innovation

[29] Gallup, 1-29. Kahn (1990). Psychological conditions of personal engagement and disengagement at work. Academy of Management Journal.

[30] Kaliannan, M. \& Adjovu, S. N. (2014). Wining the talent war via effective employee engagement: A case study. Journal of Business and Financial Affairs, 3(3)(3).

[31] Kang, M. \& Sung, M. (2017). How symmetrical employee communication leads to employee engagement and positive employee communication behaviors. The mediation of employee organization relationships. Journal of Communication Management, 82- 102.

[32] Karaa, D., Uysal, M., Sirgy, J. M. \& Lee, G. (2013). The effects of leadership style on employee well-being in hospitality. International Journal of Hospitality Management 349-18.
[33] Karatepe, O. M. (2013). High-performance work practices and hotel employee performance: The mediation of work engagement. Journal of Hospitality Management, 25(6), 903-921.

[34] Kazimoto, P. (2016). Employee engagement and organizational performance of retails enterprises. American Journal of Industrial and Business Management, Vol.06 No.04, 6(4)(4)

[35] Kothari, C. (2002). Research Methodology - Methods and Techniques. New Age International (P) Ltd, New Delhi

[36] Kothari, C. R. (2009). Research Methodology: Methods and Techniques. New Delhi New Age International Publishers

[37] Ladley, D., Wilkinson, I. F. \& Young, L. C. (2015). The impact of individual versus group rewards on work group performance and cooperation: A computational social science approach Journal of Business Research, Vol. 68, Issue 11, 2412-2425.

[38] Lamar, D. (2017). How to keep your employees happy and productive [Online].

[39] Lockwood, N. R. (2007). Leveraging employee engagement for competitive advantage. 2 - 11 ed.

[40] Mann, A. \& Harter, J. (2016). The worldwide employee engagement crisis Business Journal.

[41] Maslach, C., Schaufelli, W.B., \& Leiter, M.P. (2001), Job burnout. Annual Review of Psychology. 52. 397- 422.

[42] Menguc, B., Auh, S., Fisher, M. \& Haddad, A. (2013). To be engaged or not to be engaged: The antecedents and consequences of service employee engagement. Business Research, 662163 - 2170.

[43] Meyer, A. N., Fritz, T., Murphy, G. C. \& Zimmermann, T. (2014). Software developers" perceptions of productivity. International Symposium on Foundations of Software Engineering.

[44] Mertler, C. A. (2017). Action research: Improving schools and empowering educators (5th ed.). Los Angeles, CA: SAGE

[45] Mishra, K., Boynton, L. \& Mishra, A. (2015). Driving employee engagement: The expanded role of internal communications. International Journal of Business Communication, 51(2), 183-202.

[46] Mugenda, M. \& Mugenda, G. (2003). Research Methods: Quantitative and Qualitative Approaches. African Centre for Technology Studies, Nairobi, Kenya.

[47] Ongel, E. (2014). The relationship between employee engagement and organizational performance: Implementation of organizations. The International Journal of Social Sciences, 25(1)(1).

[48] Patro,C.S (2013). The Impact of Employee Engagement on Organization's Productivity. 2nd International Conference on Managing Human Resources at the Workplace, December 13-14, 2013

[49] Perrin, T. (2003). Working today: Understanding what drives employee engagement. The 2003 towers perrin talent report.

[50] Rothbard, N.P. (2001). Enriching or depleting? The dynamics of engagement in work and family roles. Admin. Sci. Q., 46: 655-684.

[51] Rothmann, S. \& Welsh, C. (2013). Employee engagement: The role of psychological conditions. Journal of the Southern African Institute for Management Scientists.

[52] Schaufeli, W. \& Bakker, A. (2004). Job demands, job resources, and their relationship with burnout and engagement: A multi-sample study. Journal of Organizational Behavior, 2522.

[53] Sharath, G. (2014). Organizational behaviour. Journal of Business Administration, 3(2)(2). Soni, B. S. (2013). Employee engagement - a key to organizational success in 21st century. Voice of Research, 1(4).

[54] Tims, M., Bakker, A. B. \& Derks, D. (2013). The impact of job crafting on job demands, job resources, and well-being. Journal of Occupational Health Psychology, American Psychological Association Vol. 18, No. 2, 230- 240.

[55] Tolera, D. (2018). Effects of employees' commitment on organizational performance at arjo didessa sugar factory. African Journal of Business Management 12(9).

[56] Vittee, K. (2015). Employee engagement lacking in South Africa [Online].

[57] Wellins, R. S., Bernthal, P. \& Phelps, M. (2017). Employee engagement: The key to realising competitive advantage. Development Dimensions International [Online].

[58] Yi, W. \& Chan, A. P. C. (2013). Critical review of labour productivity research in construction journals Journal of Management in Engineering, $30(2), 214-225$. 


\section{AUTHORS}

First Author - Christine Kananu Gitonga, PhD candidate (Human Resources Management), Masinde Muliro University of Science and Technology
Second Author - Dr. Robert Egessa, Lecturer, School of Business and Economics, Masinde Muliro University of Science and Technology 